\author{
Abstracta Iranica \\ Abstracta Iranica Revue bibliographique pour le domaine irano-aryen \\ Volume 37-38-39 | 2018 \\ Comptes rendus des publications de 2014-2016
}

\title{
Mahdokht Farjamirad. "Influence of Social Class Division on the Sasanian Burial Rituals (224-650 AD)"
}

Samra Azarnouche

\section{OpenEdition}

Journals

Édition électronique

URL : http://journals.openedition.org/abstractairanica/43499

DOI : 10.4000/abstractairanica.43499

ISBN : 1961-960X

ISSN : 1961-960X

Éditeur :

CNRS (UMR 7528 Mondes iraniens et indiens), Éditions de l'IFRI

\section{Référence électronique}

Samra Azarnouche, "Mahdokht Farjamirad. "Influence of Social Class Division on the Sasanian Burial Rituals (224-650 AD)" », Abstracta Iranica [En ligne], Volume 37-38-39 | 2018, document 2, mis en ligne le 30 décembre 2018, consulté le 27 septembre 2020. URL : http://journals.openedition.org/

abstractairanica/43499 ; DOI : https://doi.org/10.4000/abstractairanica.43499

Ce document a été généré automatiquement le 27 septembre 2020.

Tous droits réservés 
Mahdokht Farjamirad. "Influence of Social Class Division on the Sasanian Burial Rituals (224-650 AD)"

Samra Azarnouche 


\section{RÉFÉRENCE}

Mahdokht Farjamirad. "Influence of Social Class Division on the Sasanian Burial Rituals (224-650 AD)" in G. Affanni, C. Baccarin, L. Cordera, A. Di Michele, K. Gavagnin (eds.). Broadening Horizons 4: A Conference of Young Researchers working in the Ancient Near East, Egypt and Central Asia. University of Torino, October 2011, Oxford: Archaeopress, 2015, p. 149-153 (BAR International Series 2698).

1 L'allusion du Wīdēwdād au dépôt des ossements dans des osthothèques ou à l'air libre (Wd 6.50 : «il faut faire un édifice » à l'abri des animaux et de la pluie; Wd 6.51: « les mazdéens qui le peuvent doivent les déposer soit sur des pierres, soit sur de la chaux, soit sur de l'argile, et s'ils ne le peuvent pas, qu'ils les déposent sur le sol»), laisse entendre que, dans les modes d'inhumation, le statut financier prévalait sur l'appartenance sociale. Se concentrant sur les ossuaires rupestres de Kuh-e Rahmat, Kuh-e Ḥossein et Bīšāpūr, situés en périphérie de villes de prestige habitées par des membres fortunés de la famille royale ou de la classe sacerdotale, l'A. émet l'hypothèse que l'importance politique et religieuse de ces sites permet d'attribuer ces aménagements funéraires à ces hauts personnages. La tendance croissante à aménager des réceptacles pour les membres des hautes classes renverrait au développement de la division des classes à la fin de la période sassanide.

2 En l'absence de datation précise, de typologie et de cartographie complètes des aménagements funéraires sassanides, cette tentative peine à convaincre. Par ailleurs, les hiérarchies sociales de la noblesse et de l'aristocratie sassanide auraient sans doute fourni une meilleure grille d'analyse que la tripartition symbolique des classes.

\section{AUTEURS}

\section{SAMRA AZARNOUCHE}

EPHE, Mondes iranien et indien, Paris 